\title{
Behavior patterns in pigeons during autoshaping with an incremental conditioned stimulus
}

\author{
T. JAMES MATTHEWS and BARBARA E. LERER \\ New York University, New York, New York
}

\begin{abstract}
Pigeons were trained on a variant of the autoshaping procedure in which a keylight stimulus of increasing brightness was used to signal the passing of a 30-sec interfood interval (IFI). Keypecking developed in all subjects within the first session (65 trials). Within trials, pecking began midway through the IFI, increased throughout the remainder, and decreased just before food delivery. Other behavioral stereotypies were also recorded: Low light levels were associated with a retreat to the rear of the test chamber, and medium light levels (during the midportion of the IFI) were associated with high rates of pacing toward and away from the food source. Probe trials revealed that pecking, pacing, and retreat were all under strong stimulus control; that is, when the light was held constant at its lowest or highest brightness, or when the brightness ramp was presented in reverse order, the behavior pattern almost invariably remained tied to stimulus brightness. Results are discussed in terms of associative and nonassociative sources of the form and sequential characteristics of the behavior.
\end{abstract}

When hungry pigeons are periodically presented with food, stereotypic behavior patterns emerge during the intervals between feedings; these stereotypic patterns consist of interim and terminal components (Killeen, 1975; Skinner, 1948; Staddon \& Simmelhag, 1971). Terminal behavior, occurring immediately prior to food delivery, is related to the consummatory response that will be elicited by the reinforcer (Blaine, Innis, \& Staddon, 1980; Reberg, Innis, Mann, \& Eizenga, 1978; Staddon, 1977), and includes such activities as pecking and hovering about the food hopper. Interim behavior occurs when the probability of reinforcement is low, and may be unrelated to the behavior elicited by the reinforcer (Staddon \& Simmelhag, 1971). Examples of interim behavior are grooming, pacing, exploratory behavior, and wheel running.

Certain basic questions about the functional origin of these behavior classes remain unresolved. Interim and terminal behavior have been attributed to either associative or nonassociative origins or both. No principle of elicitation, however, provides an adequate nonassociative account for stereotypy. Among associative accounts, neither operant nor Pavlovian theory can fully account for all aspects of stereotypic behavior. Skinner (1948) offered superstitious conditioning as an operant explanation of stereotypic behavior. He observed that pigeons on fixedtime (FT) schedules of reinforcement developed idiosyncratic but stable behavior patterns and concluded that

The work described here was supported by Grant BNS77-19037 awarded by the National Science Foundation to New York University (T. James Matthews, principal investigator) and predoctoral fellowship 1 F32 MH07312 to Barbara E. Lerer. The authors are grateful to J. Anthony Movshon for his technical and statistical assistance and to Robert W. Allan for graphics, comments on the manuscript, and general helpfulness. Reprint requests may be sent to the senior author at the Department of Psychology, New York University, 6 Washington Place, New York, NY 10003. accidental coincidences of behavior and food presentation had reinforced randomly different patterns in each pigeon. Recently, however, Timberlake and Lucas (1985) questioned this observation when, like Staddon and Simmelhag (1971), they observed that pigeons on FT schedules developed remarkably similar stereotypy. Although they used this observation to reject the superstitious conditioning interpretation, one could argue that the superstitious conditioning process would favor behavior patterns with the highest spontaneous frequencies and that these patterns may be very similar among members of a given species. Nevertheless, to account for interim behavior, the operant hypothesis must be elaborated into superstitious chaining, whereby the terminal responses would serve as conditioned reinforcers for those interim responses that accidentally precede them. In this way, a chain of responses could extend through the entire interval between successive food presentations.

A more experimental attack on the operant interpretation was made by Williams and Williams (1969), who showed that the autoshaping procedure, which typically involves signaled noncontingent food presentations, generated keypecking despite an omission contingency that canceled food presentations on trials in which a keypeck occurred. This result seemed to make it clear that pecking at a signal for food would occur despite the explicit preclusion of accidental reinforcement for that response. It also seemed to show that, however keypecking was generated, it was surprisingly insensitive to its food-canceling consequences. The first supposition was undermined by Wessels (1974), who showed that keypecking in the omission procedure may be an involuntary sequel to a superstitiously conditioned orientation response. The second supposition was disconfirmed by Allan and Matthews (1982). Their modified omission contingency provided feedback for each response, which effectively suppressed respond- 
ing and demonstrated that autoshaped keypecks were sensitive to their consequences. In all, the operant interpretation of the feeding stereotypy has not been discounted.

An alternative associative account of behavioral stereotypy derives from the Pavlovian principle of stimulus substitution. It suggests that stereotypies may be conditioned responses (CRs) to conditioned stimuli (CSs) that predict food presentation (an unconditioned stimulus, or US), and predicts that their form should approximate the form of the unconditioned responses (URs). In Brown and Jenkins's (1968) autoshaping procedure, pigeons pecked at both the food reward (US) and the keylight (CS), and Staddon and Simmelhag (1971) reported that pecking frequently preceded food delivery in their temporal conditioning procedure. This argument is further strengthened by Jenkins and Moore's (1973) observation that the distinct feeding responses to food and water USs were reflected in the form of the autoshaped pecking to the respective CSs associated with these USs.

There have been, however, reports of terminal behavior forms that bore no obvious similarity to the behavior elicited by the reward. Timberlake and Grant (1975), for example, showed that a food US supported rat social responses to a social CS, and Timberlake and Lucas (1985) reported that, in many pigeons, temporal conditioning procedures produced stable terminal behavior that did not include pecking. In addition to its inability to account fully for terminal behavior forms, the stimulus substitution principle is even less applicable to interim behavior, which does not correspond in form to a food-induced UR or in temporal distribution to a Pavlovian $\mathbf{C R}$.

Interim behavior has been accounted for in terms of elicited behavior. Killeen (1975) proposed that interim behavior expresses a general arousal state induced by periodic food presentations to a hungry subject. The homogeneity of the arousal display across subjects and experiments (Palya, 1985; Staddon \& Simmelhag, 1971; Timberlake \& Lucas, 1985) can perhaps be attributed to species-specific displays of foraging or food-induced arousal. Along similar lines, Falk (1971) argued that adjunctive behavior, which is akin in many respects to interim behavior, may be related to derived behavior (Tinbergen, 1952), the instinctive reaction to a conflict between competing motivations or to the thwarting of a single motivation (as may occur when feeding is thwarted by removal of the grain hopper).

Essential to the separation of associative and nonassociative factors is the determination of the function of the time between feedings. In associative terms, behavior is tied to time as a predictor of the next food presentation; that is, time is a discriminative or conditioned stimulus. In nonassociative terms, behavior is tied to the preceding food presentation (the releasing stimulus) and is independent of time. In the FT schedule, or temporal conditioning procedure, these two functions of time are indistinguishable.

In the present experiment, an explicit $\mathrm{CS}-\mathrm{a}$ keylight of increasing brightness-was used to provide a cue for the passage of time between successive reinforcers. The method is similar to that used in operant conditioning by Ferster and Skinner (1957) and in an FT schedule by Palya (1985), but it involves the use of a gradually changing stimulus rather than a sequence of discrete stimuli. This feature gives the stimulus a closer correspondence to time, a presumably continuous stimulus, but allows adjustments analogous to manipulating time, that is, causing time to run out of sequence (stop, jump forward, run backward). To test for the degree of stimulus control exerted by this procedure over all elements of the stereotypy, well-trained subjects were presented with trials in which the light decreased or remained high or low. If elements of the stereotypy are elicited (nonassociative) in character, they should occur in time after reinforcement and not be affected by the test trials. Similarly, if the behavior patterns are superstitiously acquired chains of responses, they too should continue to unfold following reinforcement and to be unaffected by the test trials. Finally, if the behavior were to remain tightly associated with the stimulus intensity on the test trials, then it could be inferred that the behavior is under the control of the signal value of the stimulus, which suggests a Pavlovian process.

\section{METHOD}

\section{Subjects}

The subjects were 4 naive male White Carneaux pigeons about 1 year old at the beginning of the experiment. They were maintained at about $80 \%$ of their free-feeding weight throughout the experiment and were individually housed, with water and grit freely available in the home cage.

\section{Apparatus}

The subjects were tested in a standard pigeon experimental chamber located in a ventilated and sound-attenuated room. The experimental chamber was fitted with an activity floorboard (described below). The houselight was unlit during experimental sessions. I1lumination was provided by a $60-\mathrm{W}$ bulb mounted above the test chamber. White noise masked extraneous sounds, and the ambient noise level in the chamber during testing measured 73 to $74 \mathrm{~dB}$.

The top of the chamber was transparent Lucite to allow video monitoring. The video recording system and a Plessey Micro-1 LSI computer, which programmed experimental events and recorded data, were located in an adjacent room.

The floorboard. The $48.9 \times 35.5 \mathrm{~cm}$ chamber floor was constructed of nine $16.2 \times 12.1 \times 0.03 \mathrm{~cm}$ clear Lucite panels (see Figure 1). Each panel was balanced on the actuator arms of four microswitches, one switch beneath each corner, and was wired so that closure of any switch signaled the computer that the panel was depressed.

It was possible for a pigeon to close up to four panels simultaneously by standing at the junction of adjacent panels. However, the size of individual panels was such that a pigeon had its feet entirely on a single panel when it was standing comfortably eating from the hopper.

A removable sheet of lightweight opaque uphoistery vinyl covered the floorboard to protect the microswitches and wiring. The covering had the added advantage of keeping pigeons from slipping on the smooth surface of the panels or catching their claws in the spaces between the panels. 
There were nine output lines from the floorboard, each corresponding to one panel location. These were connected to the computer, which stored the onset and offset time of each panel depression.

The response key. The response key was transilluminated by five Hewlett-Packard yellow LED light bars (HLMP-2450) arranged in a solid $1.9-\mathrm{cm}$ square and mounted behind the $1.6-\mathrm{cm}$-diam translucent response key. The LED square was illuminated by a $60-\mathrm{Hz}$ train of rectangular pulses, with train duration modulated by the computer. Because the frequency of the pulses exceeded the temporal resolution limit of vision (Cornsweet, 1970), the display appeared to be steadily illuminated, with a brightness proportional to the duration of the pulse.

\section{Procedure}

Phase 1. An experimental session began with a 3-sec hopper presentation. There were 65 trials per session, each trial consisting of a 30-sec interfood interval (IFI) followed by a 3-sec hopper presentation. During the IFI, the response key brightened each second according to the process described above. This phase lasted for 19 sessions.

Phase 2. On five successive daily sessions, three types of probe trials were interspersed among the regular trials of increasing keylight brightness. During the dim probe trials the response key was illuminated for the entire IFI at the lowest brightness level of the regular trials. On bright trials, the response key was held at the brightest level of the regular sequence for the entire IFI. The third type of probe trial consisted of a reverse brightness ramp, with the keylight brightest at the start of the IFI and dimming as the trial progressed.

A total of six probe trials, two of each type, were presented during each test session. The probe trials ended in a 3 -sec time-out during which the response key was unlit and no reinforcer was presented. Each session also included 59 regular trials, for a total of 65 trials. All regular trials ended with $3 \mathrm{sec}$ of reinforcement. The sequence of trials in a session was modified random; each session began with a minimum of 10 regular trials and each probe trial was followed by at least 1 regular trial.

\section{RESULTS}

\section{Phase 1}

The data were analyzed by collapsing across the IFI into 103 -sec time bins, with each time bin representing 1/10 of the IFI or three 1-sec brightness levels.

The observed behavioral stereotypy had three distinct components: At the beginning of the IFI, in the period immediately following the removal of the food hopper used in the previous trial, the subjects retreated to the back of the chamber. After several seconds, they returned to the front of the chamber and paced along the wall containing the response key and food hopper. Pacing peaked about the middle of the IFI. Keypecking began as pacing frequency decreased and reached a maximum rate in the 9th and 10th bins, about 3-6 sec before reinforcement delivery.

The results of the last five sessions are presented graphically in Figure 2. Activity, defined as the number of panel closures per minute, is plotted as a function of elapsed trial time. Activity on the front three panels of the chamber, where most, if not all, of the pacing occurred, is represented by the solid curve. The curve provides a good indication of the distribution of pacing in the IFI.

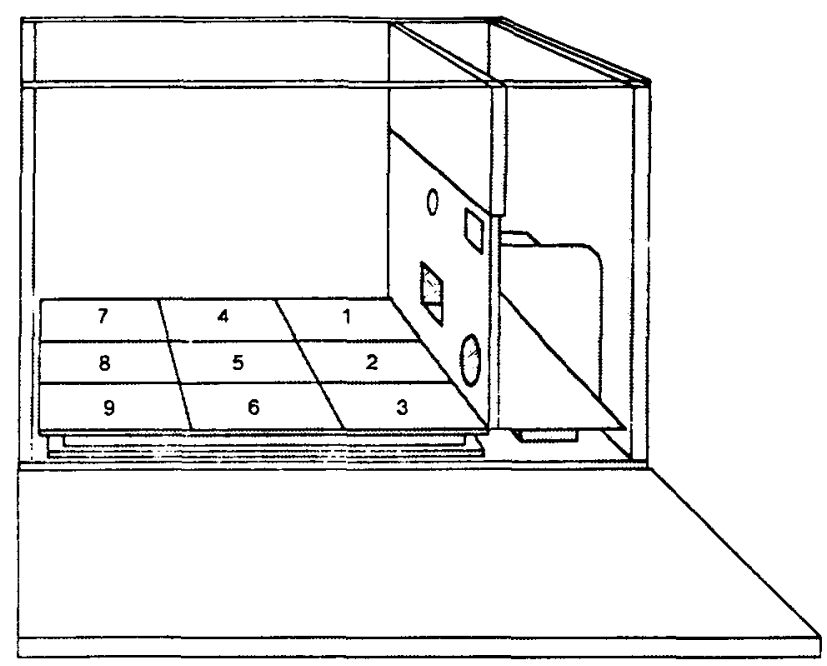

Figure 1. Experimental chamber with sctivity floorboard.

The dashed curve represents the sum of activity on Panels 4-9. This curve represents what was described as retreat, or locomotion away from the front of the chamber. Most retreat excursions went as far as the middle row of panels (4-6), and a few reached the rear row (7-9).

The distribution of keypeck interresponse times (IRTs), which measured changes in pecking rate over the IFI, was plotted as the logarithm of successive IRTs as a function of elapsed trial time, using the Continuous Log of OnGoing Events (CLOOGE) method (Chung, Raymond, \& Lettvin, 1970). Each point on the CLOOGE graphs represented the occurrence of a keypeck at a particular time within a trial, and the vertical displacement of the point indicated the duration of the interval between the keypeck and the preceding keypeck in that trial. IRTs for individual subjects during a sample session are shown in Figure 3, using the data from the last $\mathbf{1 0}$ trials of the final session of Phase 1.

The IRT analysis revealed a distinctly nonrandom distribution of IRT scores. The distributions for all birds were

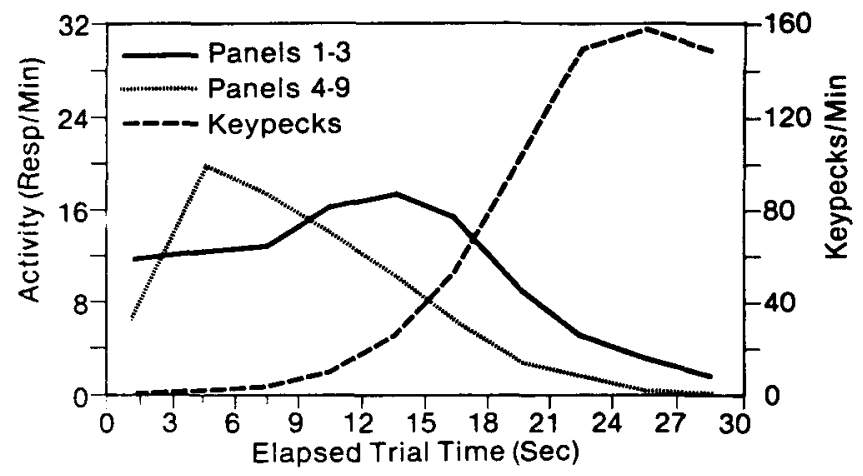

Figure 2. Frequency distributions of intratrial pecing on Panels 1-3 (solid line, left axis), retreat on Panels 4-9 (dotted line, left axis), and keypecking (dashed line, right axis). 


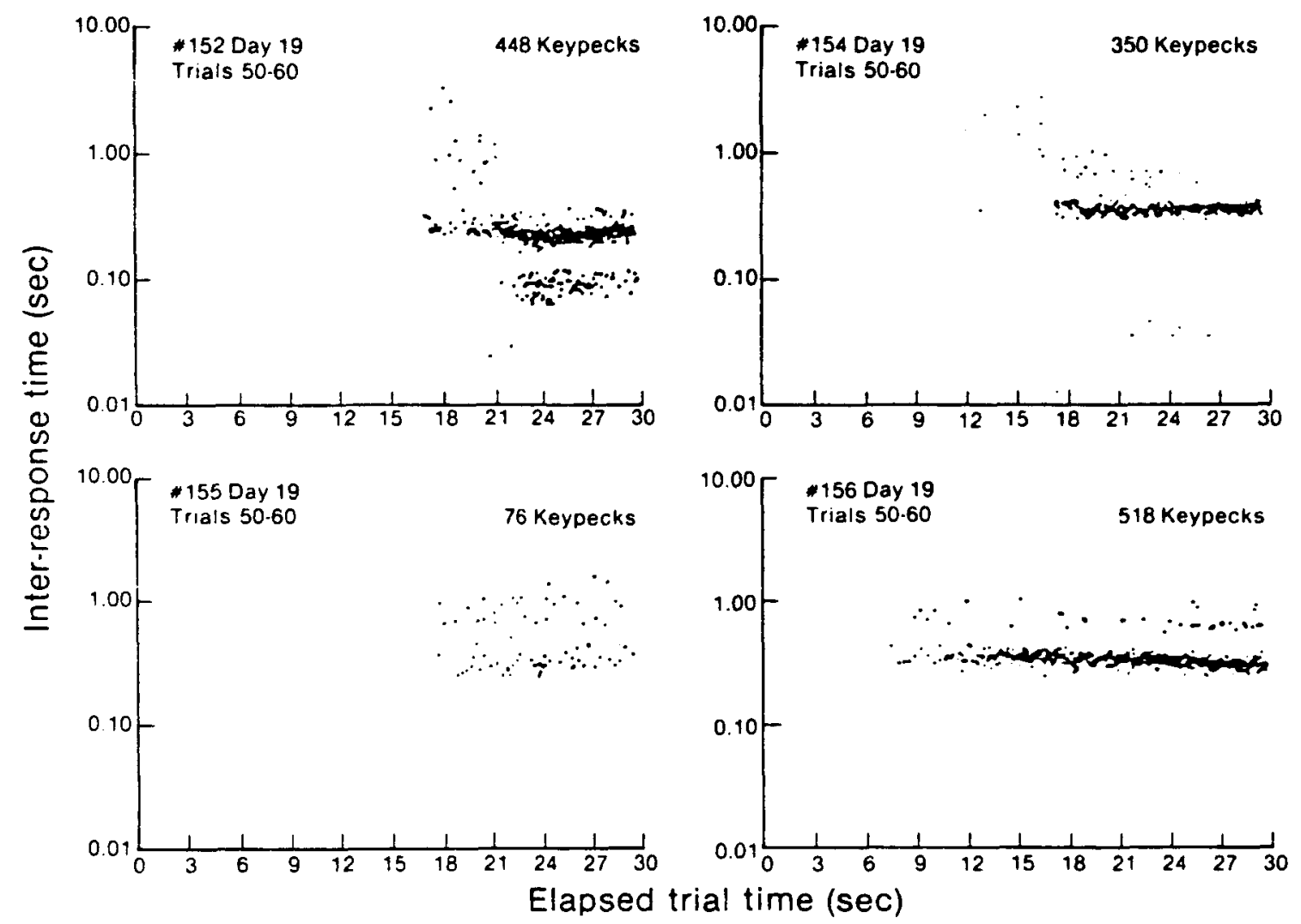

Figure 3. Successive interresponse times (IRTs) for individual keypecks. The vertical axis represents the IRT and the horizontal axis represents the elapsed trial time. Each panel includes the keypeck data for 10 trials in a single session; the first keypeck in each trial is omitted from the analysis.

dominated by a single narrowly defined IRT band, which was that modal value throughout the trial. Subjects 152 and 154 initiated pecking on some trials with long IRTs but soon assumed stable high rates. The other 2 subjects initiated pecking at a high rate and sustained that rate through the IFI. For 3 subjects, the overall distribution of IRTs was bimodal, which indicates pecking in bursts with regular pauses between bursts. For Subject 152, however, very short IRTs were interspersed in an otherwise stable response rate, which probably indicates "double pecking" caused by separate impact from the upper and the lower mandible (Blough, 1963). Bimodal distributions of IRTs have also been reported with instrumental responding (Blough, 1963; Hodos, 1963; Ray \& McGill, 1964). This statistical characteristic of our data requires that changes in overall rate during the later bins in the IFI be interpreted as shifts in the relative proportions of the modal IRT, rather than as a shift in the overall IRT distribution.

\section{Phase 2}

The stereotypy observed during the regular trials with incremental key brightness (Figure 4A) was indistinguishable from the stereotypy described in Phase 1 (Figure 2); however, very different patterns of behavior emerged on probe trials. Figure $4 \mathrm{C}$ shows that few keypecks were emitted on dim trials, and these occurred at the end of the IFI. Activity at the front and back of the chamber persisted at high rates throughout the IFI. The predominant activity involved repeated circling around the chamber, which is represented graphically by the overlapping lines representing the front and back panels of the floorboard.

On bright trials (Figure 4D), keypecking began immediately with keylight illumination at the start of the IFI. Pecking reached its maximum rate of about two pecks per second in the third time bin and continued at a somewhat slower rate until the end of the trial. At no point did pecking reach the maximum rates seen in the last bins of regular trials. There was very little pacing and no postreinforcement retreat to the back of the chamber.

The emergent patterns on reverse ramp trials approximated a mirror image of the patterns on the regular trials (see Figure 4B). Pecking began at the beginning of the IFI when the keylight was brightest, peaked after 9-12 sec (in the fourth bin), and decreased in frequency thereafter. Few keypecks were emitted at the end of the IFI, when the keylight was dim. Pacing remained at a constant low rate until about midway through the IFI. As the pecking rate dropped, pacing increased sharply, continued at a high rate as the trial progressed, and reached its maxi- 


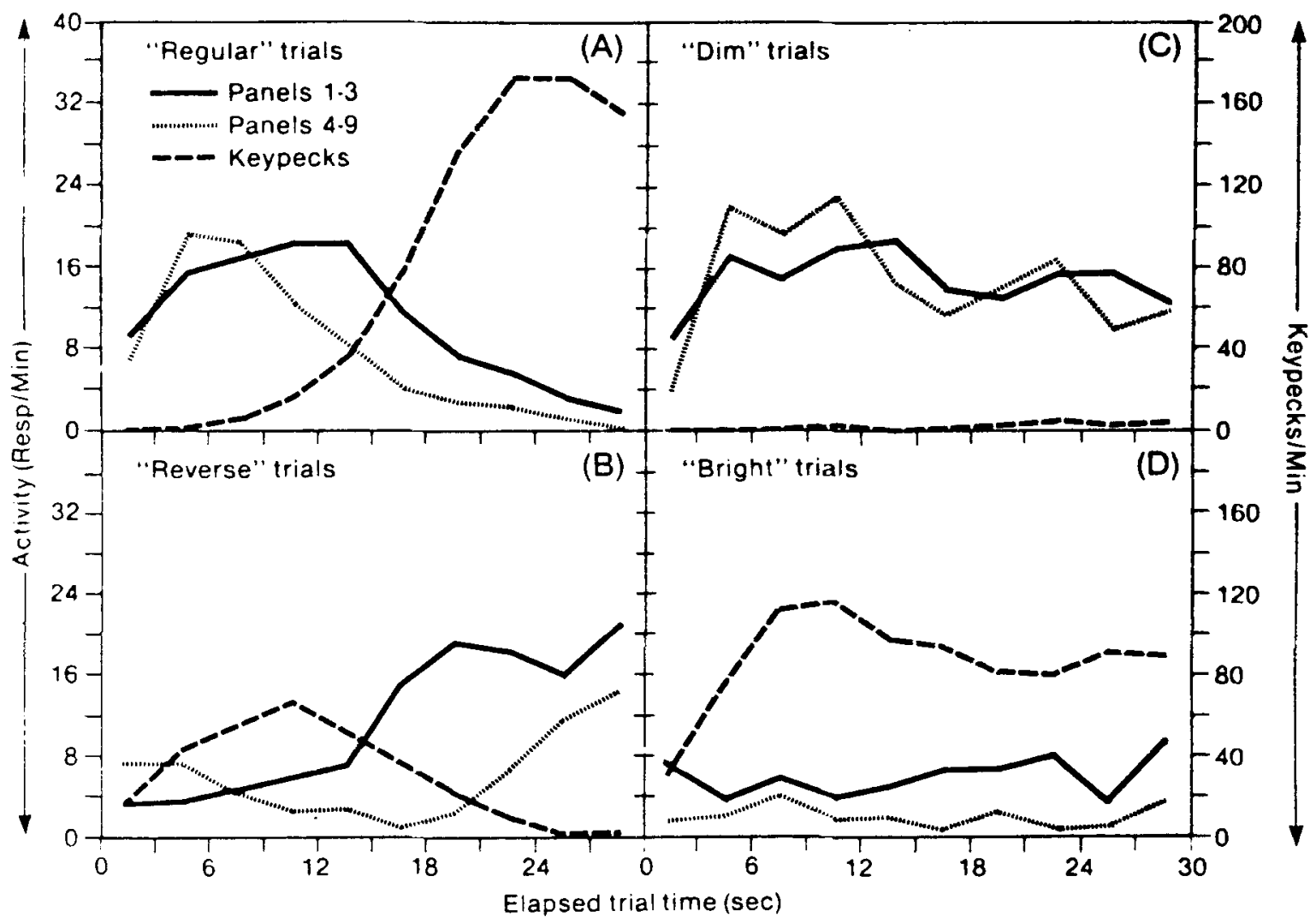

Figure 4. Floorboard activity (mean panel closures/min) in the front (solid line, left axis) and back (dotted line, left axis) of the experimental chamber, and rate of keypecking (dashed line, right axis) during regular reinforced trials (A), and reversed (B), dim (C), and bright (D) probe trials. See text for descriptions of the probe trial procedures.

mum at the end of the IFI, when the keylight was dimmest. Activity in the back of the chamber was minimal until about the eighth time bin; then, as the keylight dimmed, retreat behavior increased in frequency and reached its maximum rate in the last time bin, when the keylight was dimmest.

\section{DISCUSSION}

The changing brightness of the response key over time served as an incremental CS in this experiment and elicited autoshaped keypecking as a terminal response. Autoshaping experiments have traditionally used discrete CSs and well-defined intertrial intervals (Balsam \& Payne, 1979; Brown \& Jenkins, 1968; Gibbon, Baldock, Locurto, Gold, \& Terrace, 1980; Hearst \& Jenkins, 1974; Terrace, Gibbon, Farrell, \& Baldock, 1975); nevertheless, the incremental CS used here was an effective elicitor of autoshaped pecking. The pattern of responding was consistent with the results of experiments using serial discrete stimuli (Palya, 1985; Ricci, 1973). Keypecking was initiated near the midpoint of the IFI and reached a peak near the time of food delivery.

Measures of activity revealed two distinct behavior pat- terns during the IFI that closely resembled those observed previously on FT schedules. For example, immediately after reinforcement, the subjects often circled to the rear of the chamber (retreat). This behavior, which was described by Staddon and Simmelhag (1971) as an interim behavior, has been observed in similar experiments (see Pear, 1985; Timberlake \& Lucas, 1985; Wasserman, Franklin, \& Hearst, 1974, Experiment 1; Yoburn \& Cohen, 1979; Yoburn, Cohen, \& Campagnoni, 1980). Following retreat, the subjects paced along the front or side wall in a repetitive pattern; pacing reached a peak frequency near the midpoint of the interval. This pattern also has been described, and classified as an interim behavior, by Staddon and Simmelhag (1971), Killeen (1975), and Timberlake and Lucas (1985), among others. The sequence of behaviors reliably produced by the ramp training procedure was (1) retreat, (2) pacing, and (3) keypecking; these behaviors represent a combination of the behavioral effects of the discrete trial autoshaping procedure and the FT schedule.

In Phase 2, the keylight stimulus was manipulated to alter the subjective perception of reinforcement imminence, and the results showed that the three behavior classes (retreat, pacing, and pecking) were under tight 
stimulus control. The dim trials produced sustained retreat activity at the rear of the chamber, the bright trials produced a high level of pecking and very little retreat or pacing, and the reverse trials resulted in a reversal of the order in which the behavior classes occurred.

An interpretation of retreat as an elicited behavior is contradicted by the substantial reduction in retreat during the bright probe trials, the occurrence of retreat at the end, rather than at the beginning, of the reverse probe trials, and the sustained retreat activity in the dim probe trials. If retreat resulted from an elicitation process, then it should have had the same decay function in probe trials as in regular trials. Rather, it appears that retreat behavior was largely a response to a signal of low reinforcement imminence, which suggests an associative interpretation of the functional basis of the retreat stereotypy.

An interesting result of the probe trials is the reversed stereotypy seen during reverse trials. This reversal suggests that superstitious chaining could not account for the feeding stereotypy, because behavioral chains rely heavily on response-produced feedback, with each component of the chain setting the occasion for the subsequent component. The observed reversal of the behavioral sequence indicates that response feedback was entirely subordinate to control by the keylight stimulus; this situation could not be predicted by operant theory.

In general, it appears that a Pavlovian interpretation offers a better associative account of stereotypy than does operant theory. However, the principle of stimulus substitution is only partially upheld by the dafa. Although the keypecking terminal response is consistent with the expectations of the stimulus substitution principle, the interim retreat and pacing violate the principle, as neither bears an apparent correspondence to the food UR. Two variations on the Pavlovian theme, however, can be made to account for the data. The first variation preserves the stimulus substitution principle by suggesting that the UR for retreat and pacing was not the response to food presentation (i.e., eating), but rather a behavioral reaction to food withdrawal. This might include flight or locomotor behavior, which are constituents of pigeon foraging behavior (Whitman, 1898). With repeated trials, as in Phase 1 , this behavior could have been conditioned to the brightness values with which it coincided. During testing with the reverse or bright probes, the beginning of the IFI induced conflict in the subject-should the pigeon follow the eliciting properties of the situation, or the message of the CS? Our data suggest CS domination over the presumptive USs; that is, the behavior observed was related to brightness level, and not to withdrawal of the preceding reinforcer. In summary, the form of retreat and pacing stereotypy may imply embedded Pavlovian contingencies in which postfood reactions serve as URs for the development of locomotor CRs.

The second variation is based on Bindra's (1974) concept of the $C R$, which extends beyond the substitution principle in that the well-formed CR includes more than a facsimile of the final consummatory act and may recapitulate the entire taxic sequence associated with the food
US. As the incremental CS grows brighter, it signals differing proximities of reinforcement, and the behavior that occurs at each brightness is appropriate to the signaled proximity of reinforcement. For example, the dim light signaled an abrupt depletion of the likely food supply, and the subjects retreated from the food site. The bright light signaled immediate prospects of food, and the subjects focused their activity toward the food site and pecked the food signal; in the midrange of the incremental stimulus, the subjects scurried around near the food source, perhaps in some approximation of natural foodseeking behavior.

This interpretation suggests that the explicit form of the stereotypy may derive from the naturally occurring repertoire of foraging behavior. The stereotypy that occurs in conditioning experiments may be quite substantially transformed by the peculiar circumstances that confront the pigeon in a Skinner box, but if the translational rule were known, the origins of the form of stereotypy might be found. This possibility encourages the comparative study of naturally occurring and experimentally constrained feeding stereotypies.

Overall, our results do not support an operant interpretation of any aspect of the feeding stereotypy. Furthermore, it appears that, after extended training, the stereotypy was not directly elicited by the reinforcer or by reinforcer withdrawal. Rather, it appears that behavioral stereotypy is most easily interpreted as a set of Pavlovian conditioned responses. The traditional version of Pavlovian theory cannot account for the form of the stereotypy, but variations on the theory offer some promising new approaches.

\section{REFERENCES}

Allan, R. W., \& Matrhews, T. J. (1982). Associative and elicited factors in the modulation of food and uater induced stereotypies. Paper presented at the meeting of the Eastern Psychological Association, Baltimore.

Balsam, P. D., \& Payne, D. (1979). Intertrial interval and unconditioned stimulus durations in autoshaping. Animal Leaming \& Behavior, 7, 477-482.

BINDRA, D. (1974). A motivational view of learning, performance and behavior modification. Psychological Review, 81, 199-213.

Blaine, C., Innis, N. K., a Staddon, J. E. R. (1980). Stimulus control of behavior induced by periodic schedule of food presentation in pigeons. Bulletin of the Psychonomic Society, 16, 131-134.

BLough, D. S. (1963). Interresponse time as a function of continuous variables: A new method and some data. Joumal of the Experimental Analysis of Behavior, 6, 237-246.

Brown, P. L., Jentins, H. M. (1968). Auto-shaping the pigeon's key-peck. Joumal of the Experimental Analysis of Behavior, 11, 1-8.

Chung, S. H., Raymond, S. A., Lettvin, J. Y. (1970). Multiple meaning in single visual units. Brain Behavior \& Evolution, 3, 72-101.

CoRnsweet, T. N. (1970). Viswal perception. New York: Academic Press.

FALX, J. L. (1971). The nature and determinants of adjunctive behavior. Physiology \& Behavior, 6, 577-588.

Ferster, C. B., \&xinner, B. F. (1957). Schedules of reinforcement. New York: Appleton-Century-Crofts.

Gibbon, J., Baldock, M. D., Locurto, C., Gold, L., \& Terrace, H. S. (1980). Trial and intertrial durations in autoshaping with pigeons. Animal Learning \& Behavior, 8, 45-59.

HeArst, E., \& Jenxins, H. M. (1974). Sign-tracking: The stimulus- 
reinforcer relation and directed action. Austin, TX: Psychonomic Society.

HoDos, W. (1963). A simple method for the description of interresponse time distributions. Journal of the Experimental Analysis of Behavior, $6,90$.

JenkIns, H. M., * MoORE, B. R. (1973). The form of the autoshaped response with food or water reinforcers. Journal of the Experimental Analysis of Behavior, 20, 163-181.

KILLEEN, P. (1975). On the temporal control of behavior. Psychological Review, 82, 89-115.

PALYA, W. A. (1985). Sign-tracking with an interfood clock. Joumal of the Experimental Analysis of Behavior, 43, 321-330.

Pear, J. J. (1985). Spatiotemporal patterns of behavior produced by variable-interval schedules of reinforcement. Joumal of the Experimental Analysis of Behavior, 44, 217-233.

RAY, R. C., MCGiLL, W. (1964). Effects of class-interval size upon certain frequency distributions of interresponse times. Joumal of the Experimental Analysis of Behavior, 7, 125-127.

Reberg, D., Innis, N.K., Mann, B., Eizenga, C. (1978). “Superstitious" behavior resulting from response-independent presentations of food or water. Arimal Behavior, 26, 507-519.

RiccI, J. A. (1973). Key pecking under response-independent food presentation after long simple and compound stimuli. Journal of the Experimental Analysis of Behavior, 19, 509-516.

SKTNNER, B. F. (1948). Superstition in the pigeon. Joumal of Experimental Psychology, 38, 168-172.

Staddon, J. E. R. (1977). Schedule-induced behavior. In W K. Honig \& J. E. R. Staddon (Eds.), Handbook of operant behavior. Englewood Cliffs, NJ: Prentice-Hall.

Staddon, J. E. R., SmmelaAg, V. (1971). The "superstition" experiment: A re-examination of its implications for the principles of adaptive behavior. Psychological Review, 78, 3-43
Terrace, H. S., Gibbon, J., Farrell, L., \& Baldock, M. D. (1975). Temporal factors influencing the acquisition and maintenance of an autoshaped keypeck. Animal Leaming \& Behavior, 3, 53-62.

Tmmerrake, W., Grant, D. L. (1975). Autoshaping in rats to the presentation of another rat predicting food. Science, 190, 690-692.

Tmabrlake, W., \& Lucas, G. A. (1985). The basis of superstitious behavior: Chance contingency, stimulus substitution, or appetitive behavior? Joumal of the Experimental Analysis of Behavior, 44, $279-301$. TrNbERGEN, N. (1952). “Derived" activities: Their causation, biological significance, origin, and emancipation during evolution. Quarterty Review of Biology, 27, 1-32.

Wasserman, E. A., Franklin, S. R., \& Hearst, E. (1974). Pavlovian appetitive contingencies and approach vs. withdrawal to conditioned stimuli in pigeons. Joumal of Comparative \& Physiological Psychology, 86, 616-627.

Wessels, M. G. (1974). The effects of reinforcement upon the prepecking behaviors of pigeons in the autoshaping experiment. Joumal of the Experimental Analysis of Behavior, 21, 125-144.

Whitman, C. O. (1898). Animal behavior. Biological lectures from the Marine Biological Laboratory of Woods Hole, 6, 285-338.

Williams, D. R., \&illiams, H. (1969). Auto-maintenance in the pigeon: Sustained pecking despite contingent non-reinforcement. Journal of the Experimental Analysis of Behavior, 12, 511-520.

YoBURN, B. C., \& CoHEN, P. S. (1979). Assessment of attack and drinking in White King pigeons on response food schedules. Journal of the Experimental Analysis of Behavior, 31, 91-101.

Yoburn, B. C., Cohen, P. S., Campagnoni, F. G. (1981). The role of intermittent food in the induction of attack in pigeons. Journal of the Experimental Analysis of Behavior, 36, 101-117.

(Manuscript received June 13, 1986;

revision accepted for publication November $24,1986$. 